\title{
EVALUATING THE DETERIORATION OF GEOTECHNICAL INFRASTRUCTURE ASSETS USING PERFORMANCE CURVES
}

\author{
K.M. Briggs ${ }^{1 *}$, T.A. Dijkstra ${ }^{2}$ and S. Glendinning ${ }^{3}$ \\ ${ }^{I}$ Department of Architecture \& Civil Engineering, University of Bath, Bath, UK \\ ${ }^{2}$ School of Architecture, Building \& Civil Engineering, Loughborough University, Loughborough, UK \\ ${ }^{3}$ School of Engineering, Newcastle University, Newcastle, UK \\ * Corresponding author
}

\begin{abstract}
Long Linear (geotechnical) Assets (LLAs) are a major component of the physical infrastructure required to deliver critical services over long distances. This existing, physical transport infrastructure is at various stages of performance and deterioration, some of which is in a poor state or reaching the end of life. This paper describes a framework for understanding deterioration processes and then evaluates the use of curves to map the performance of LLAs forming the UK's transport infrastructure network. Detail was added to generic performance curves by considering the peer-reviewed evidence for the drivers, properties and mechanisms causing a loss of soil strength in transport infrastructure embankments. The results show that performance curves can be used to evaluate the performance of LLAs over their lifetime, to consider specific definitions of performance and to compare asset types. They provide a common language to communicate the deterioration mechanisms affecting assets or a network of assets. They provide a method to structure the planning, collection and interpretation of large volumes of 'smart' information describing the performance of long linear assets. This contributes to the UK's infrastructure vision to deliver intelligent design, management and maintenance.
\end{abstract}

\section{Introduction}

Long Linear (geotechnical) Assets (LLAs) are a major component of the physical infrastructure required to deliver critical services over long distances. These include the $c$. $20,000 \mathrm{~km}$ of earthworks (embankments and cuttings) supporting the strategic road network and railway network (Loveridge et al., 2010). This existing, physical transport infrastructure is at various stages of performance and deterioration. Some of this infrastructure is beyond the limit of the intended (or notional) design life and therefore requires constant management and maintenance.

The use of Smart Infrastructure and the growing 'digital abundance' of information (Bowers et al., 2016) offers the opportunity to transform the management and maintenance of transport infrastructure. This will help infrastructure owners to plan effectively, save money and reduce disruptions to services. However, it is challenging to interpret information describing the behaviour and performance of geotechnical structures such as earthworks. This is due to the complex relationship between the properties of the soils, the properties of the earthworks, the drivers of deterioration and the mechanisms of deterioration affecting performance.

The aim of this paper is to describe the components of the ACHILLES research framework (i) to better understand deterioration processes and their effect on asset performance, and (ii) to develop a suite of performance curves that can be used to evaluate and map the condition of Long Linear (geotechnical) Assets (LLAs) supporting the UK's transport infrastructure network. These provide a framework to evaluate smart data sources and condition indicators for LLA management.

\section{A deterioration framework}

Deterioration describes the process of something disintegrating; causing it to become worse or inferior in quality or value. When considering Long Linear Assets (LLAs), the term deterioration can be used to describe a change leading to a loss of performance with respect to an expectation. The change in performance can be driven by one or more physical processes or mechanisms acting independently or together. These can occur at the material (soil) scale, the scale of the asset (i.e. the full slope scale) and/or at the network scale. The expectation of performance can be interpreted broadly to include considerations such as the level of service (e.g. for road traffic flow or rail ride quality), the cost of ownership and maintenance, financial utilisation or regulatory compliance.

Figure 1 shows a framework for assessing the deterioration of Long Linear Assets (LLAs). Deterioration is driven by human actions including physical loading due to traffic, amplified by more intense use (e.g. frequency and axle-load), and secondary loading from associated structures or adjacent land. It is also driven by environmental actions including seasonal pore water pressure cycles and changes in peak pore water pressures due to extreme weather conditions and a changing climate. These human and environmental actions change the properties of LLAs at the soil scale (e.g. a change in strength, stiffness, permeability or structure) and at the asset scale (e.g. changes 
in slope geometry or structural integrity due to deformation or failure). Although not considered here, the deterioration of LLAs can cause localised transport disruption, which then propagates throughout the national network (Jaroszweski et al., 2015).

Figure 1 A deterioration framework for Long Linear (geotechnical) Assets (LLAs)

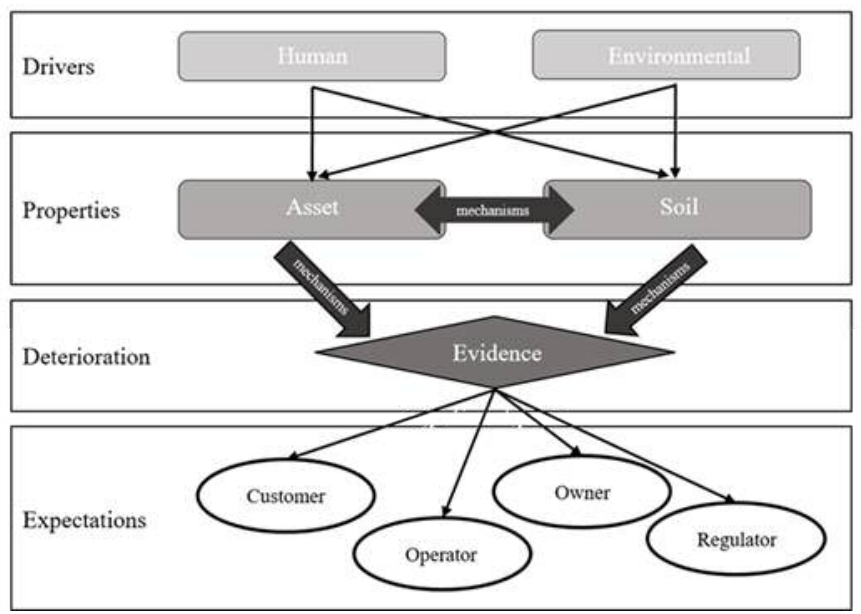

The deterioration framework (Figure 1) provides a means to contextualise the existing evidence for LLA deterioration and gather new information. It shows the need for a greater understanding of the relationship between drivers and properties and how these are indirectly linked to the expectations of performance. Additional evidence can be gathered by examining drivers and properties (the cause) or expectations (the effect). The drivers of deterioration and the properties of LLAs can be examined using laboratory experiments, cases studies, field investigations and numerical simulations. Evidence for the performance of LLAs relative to expectations can be obtained from information held by the customers, owners, operators and regulators of LLAs. This evidence might include traffic flow information, rail alignment measurements, maintenance and renewal records, cost of ownership and regulatory reports. There is potential to gather new performance information as new sensing technologies and data sources become available to LLA owners. New monitoring technologies are summarised by Smethurst et al. (2017), which include but are not limited to geophysical (Chambers et al., 2014; Gunn et al., 2016; Gunn et al., 2018) measurements of drivers, soil properties and asset properties.

\section{A deterioration model}

The performance, behaviour and the deterioration of assets over their lifetime can be described using an inverted 'bathtub' curve (Kluke et al., 2003; Thurlby, 2013). Thurlby (2013) presents a curve used to model the performance of a population of homogenous assets. Often the curve compares the hazard function (vertical axis) against time (horizontal axis) where the hazard function describes the number of failures as a percentage of the total number of assets (Thurlby, 2013). This concept can be applied to asset networks (e.g. energy and transport networks) by plotting the performance of an asset or network of assets (vertical axis) over time to produce the curve shown in Figure 2.

The curve shown in Figure 2 compares changes in different measures of performance over time. It can be used to evaluate the performance of LLAs; from the material scale, to individual assets or networks of assets. If the current age and performance of an asset or asset network is known then a curve can be used to forecast the timing and the rate of future deterioration. The curve can also be used to plan interventions that prevent deterioration and maintain or improve performance. The curve shown in Figure 2 has four broad stages consisting of i) a bedding-in period where performance improves, ii) a period of reliable performance through the life of the asset, iii) a period of deterioration and/or maintenance to improve performance, iv) a period where the asset becomes unreliable, fails or reaches the end of its life. These four stages can be used to describe the life of a Long Linear Asset (LLA) such as a railway embankment or highway cutting. They can also be used to determine the age-related condition and performance of an asset when the asset age is unknown.

Performance curves provide a conceptual model for evaluating LLAs, but it is challenging to produce curves for specific assets or networks of assets forming highway and railway networks. In the UK, the LLAs forming these networks have different performance requirements, they are of different ages, they are formed from different materials, they are subjected to different loading regimes and they have different levels of maintenance. To produce performance curves for LLAs requires an understanding of the physical process of deterioration and it requires access to accurate, consistent and reliable data. These requirements are often difficult to address when considering many types of physical assets and asset networks (Thurlby, 2013). A further challenge is that forecasts of future performance are informed by past performance and behaviour, but must account for changing drivers of deteriorations (e.g. increased traffic loading or a changing climate).

Figure 2 A curve showing the performance of an asset or network of assets over time

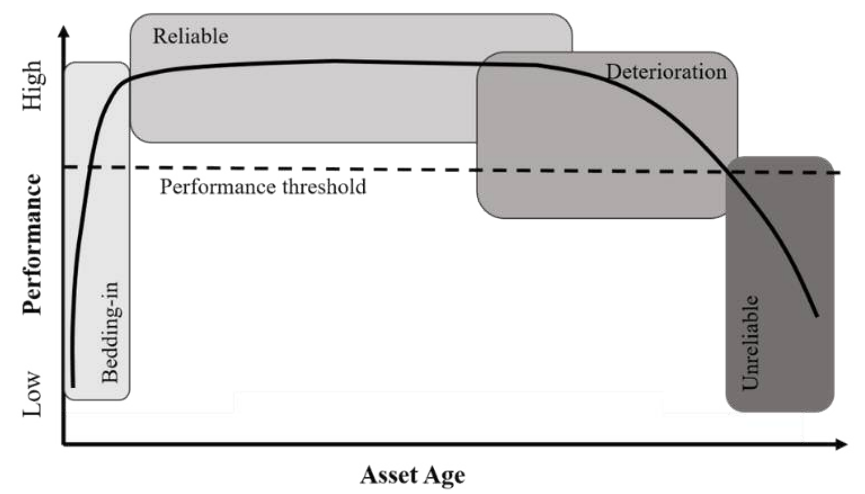

\section{Evidence for the deterioration of LLAs}

The curve shown in Figure 2 can be used for a range of performance measures and for a variety of LLAs. However a more specific example will be used in this instance for the 
purposes of illustration. The following sections present research showing the deterioration of clay fill embankments due to pore water pressure increase and cycling; driven by sequences of weather conditions (including extremes) and a changing climate. A loss of performance in this instance was defined as a loss of soil strength leading to an ultimate limit state failure of the embankment. This information was then used to map UK LLAs on to a performance curve. LLAs forming the national railway network, the strategic road network (SRN) and high-speed railway networks are considered.

\subsection{The loading factors affecting the deterioration of embankments}

The loading factors influencing a loss of performance at the slope scale can be summarised as large seasonal pore water pressure cycles and/or a pore water pressure increase to a greater magnitude or at a greater rate than historical values. Evidence from instrumented embankment sites show that they are subjected to pore water pressure cycles driven by seasonal weather conditions. Evidence from many instrumented sites (natural slopes, cuttings and embankments) shows that pore water pressures increase during the winter months in response to net water infiltration into a slope and reduce during the summer months in response to net surface drying (Blight, 1997; Leroueil, 2001).

The magnitude of the pore water pressure cycles and the depth of their influence is dependent on the short-term weather conditions, longer-term seasonal weather patterns and the presence of vegetation on the embankment slope. For example, evidence from instrumented embankments and associated numerical simulations (Anderson \& Kneale, 1980; Ridley et al., 2004; Scott et al., 2007; MacDonald et al., 2012; Smethurst et al., 2015; Briggs et al., 2016) show that tree covered slopes are subjected to a greater extent and magnitude of seasonal pore water pressure cycles than grass covered slopes. An increase in pore water pressures above historic values can trigger embankment failure. This can occur deep within embankments following periods of prolonged wet winter weather (Squire, 1880; Chandler et al., 1973; Birch \& Dewar, 2002; Ridley et al., 2004; Loveridge et al., 2010; Briggs et al., 2013; Abrams \& Brown, 2017; Tang et al., 2018), or at shallow depth in response to summer storms (Anderson \& Kneale, 1980; Vaughan, 1994; Leroueil, 2001; Dixon et al., 2018).

\subsection{The intrinsic features of embankments}

Embankments consist of fill placed to maintain the vertical alignment of road and rail routes by raising the ground level above that of the surrounding natural ground (Briggs et al., 2017). They have variable geometry, material composition and age of construction. The age, variable composition and the empirical design of Victorian-aged railway embankments makes them likely to be in the initial or advanced stages of deterioration. Highway embankments forming the strategic road network (SRN) are younger and more robust to the factors influencing a loss of performance. They are therefore likely to be at an earlier stage of deterioration or deteriorating at a slower rate than railway embankments. Embankments forming high-speed railway lines are relatively new and may be improving in performance rather than deteriorating in the short-term.

The construction of the UK's railway network began in 1827 and nine main lines of railway were built in England between 1834 and 1841 (Skempton, 1996). The embankments were designed and built empirically (e.g. Harrison, 1881). They were often rapidly constructed by end-tipping poorly compacted fill from the advancing head of an embankment and many failed soon after construction (Squire, 1880; Cooper, 1899; Vaughan et al., 2004; O'Brien, 2007), leaving relict shear surfaces and hidden zones of weakness. Most of these embankments still form the foundation of the national railway network. These embankments are therefore old (more than 150 years old), with variable geometry and historic weaknesses which may accelerate deterioration.

Highway construction in the UK began in 1958 and rapidly grew between the 1960s and 1990s (Loveridge et al., 2010). Highway embankments were designed and constructed using design standards (e.g. British Standard 6031 (British Standards Institution, 2009)) based on classical saturated soil mechanics theory and informed by extensive research into the properties of the fill construction materials (Road Research laboratory, 1952). As a result, few embankment failures occurred during or after construction. However, this has not eliminated the risk of embankment failure. Most of these embankments form the foundation of the strategic road network (SRN). These embankments are younger than those on the railway network, they are less likely to include zones of weakness and they are more homogenous in terms of their geometry and material composition. This may increase their resilience to deterioration, although many of them are now reaching the end of their planned life (60 years).

The embankments supporting the UK's high-speed railway lines are much younger than those on the national railway network or SRN. The first section of the high-speed, Channel Tunnel Rail Link (CTRL) opened in 2003. The embankments were constructed to strict track alignment tolerances for highspeed trains and designed to minimise the required maintenance and operational downtime. This was achieved using extensive ground investigation, controlled material placement and a design informed by experience from the TGV Nord (Paris-Calais) high speed railway in France (Phear \& O'Riordan, 2004). These embankments may be bedding-in, leading to an improvement in strength and stiffness because of densification under traffic loading and initial drying after compaction.

\subsection{The soil factors influencing the deterioration of embankments}

The soil factors influencing a loss of embankment performance at the soil scale and the scale of the asset can be summarised as the propensity of the soil to crack, disaggregate or soften in response to cycles of pore water pressure and soil moisture content. 
There is significant evidence showing that the strain-softening of high-plasticity clays can lead to the long term, progressive failure of clay cuttings (Skempton; 1970; Garret \& Wale, 1985; Burland et al., 1977; Potts et al., 1990; Vaughan, 1994; Potts et al., 1997; Ellis \& O'Brien, 2007). However, there is less field monitoring evidence in the literature showing this mechanism in clay fill embankments (high or low plasticity). However, numerical simulations have been used to explore the behaviour of high plasticity clay embankment slopes (Kovacevic et al., 2001; Nyambayo et al., 2004; Scott et al., 2007; Rouainia et al., 2009; O'Brien, 2013). These results show that the progressive failure and the time to ultimate failure are influenced by the number of pore water pressure cycles, the magnitude pore water pressure changes and the presence of vegetation at the slope surface.

Laboratory testing has been used to explore the deterioration of clay soils in response to cycles of pore water pressure and soil moisture content. Mendes \& Toll (2016) showed that sandy clay soil samples dried to a particular moisture content are stronger than those wetting to the same moisture content, due to hysteresis of the Soil Water Retention Curve (SWRC). Stirling et al. (2017) showed that different soil types deteriorate in different ways in response to wetting and drying cycles. For example, Marine Clays (high plasticity) developed pervasive, fine crack patterns while Glacial Tills (low plasticity) developed permanent, deep cracks. In both cases, wetting and drying cycles caused cumulative micro cracking which progressively disaggregated the soil. Hen-Jones et al. (2017) showed complementary evidence of these deterioration mechanisms at the slope-scale.

Centrifuge testing has been used to measure the deterioration of clay slopes subjected to cyclic changes in effective stress induced by wetting and drying at the slope surface (Briggs et al. 2017). The results of these experiments show that a stiff, high plasticity clay slope failed due to dilation, softening and creep in the form of downslope ratcheting; leading to a localised failure at the toe of the slope (Take \& Bolton, 2011). In contrast, the results from a centrifuge model slope constructed from compacted low-plasticity clay fill clods (Hudacsek et al., 2009) showed that the slope did not show significant shrink-swell movement and progressive failure was not observed. These results are supported by evidence showing seasonal accumulations of deformation and ratcheting, not always leading to failure, in long-term monitoring data from a clay fill embankment dam (Lees et al., 2013).

\subsection{The composite factors influencing the deterioration of embankments}

The deterioration of embankments is driven by the loading factors described above. However, this is linked to the intrinsic properties of the embankments and the soils from which they are formed. These factors can act interdependently to drive the deterioration of embankments towards failure. For example, an ageing, poorly compacted, high plasticity clay fill embankment with well-developed surface cracking, formed from a soil with a high saturated conductivity and susceptible to strainsoftening is likely to be deteriorating and at risk of failure. In contrast, a new, well-compacted, low-plasticity clay fill embankment with good foundation drainage, a low saturated hydraulic conductivity and formed from a clay not susceptible to strain-softening is less likely to be at risk of failure.

Glendinning et al. (2014) showed that the saturated hydraulic conductivity and the soil water retention characteristics of the fill influence the pore water pressure regime within an embankment. This can vary significantly between the near surface $(0.5 \mathrm{~m}$ depth) and the core of an embankment (Dixon et al. 2018). Loveridge et al. (2010) showed that the saturated hydraulic conductivity of clay fill railway embankments was close to a critical value $\left(1 \times 10^{-7} \mathrm{~ms}^{-1}\right)$, which made them more susceptible to seasonal weather changes than railway cuttings or highway slopes (embankments and cuttings). Briggs et al. (2013) showed that clay fill embankments founded on low permeability clay soils were more likely to experience rapid pore water pressure increase during periods of extreme winter weather than those underdrained by a more permeable soil. Anderson et al. (1982), Stirling et al. (2017), Hen-Jones et al. (2017) and Stirling et al. (2018) showed that desiccation cracking could dynamically alter the rate of surface water infiltration into an embankment slope. These cracks form permanent zones of weakness, which progressively alter the soil fabric over wetting and drying cycles. The presence of vegetation can further alter the soil structure, soil deformation and the movement of water within an embankment slope (Briggs et al., 2017).

\section{Discussion: Mapping an embankment performance curve}

By considering the ultimate failure of embankments driven by pore water pressure cycling (Section 4), it is possible to add informative detail to a performance curve.

Figure 3 Performance curves showing the factors influencing the ultimate limit failure of embankments due to seasonal weather cycles

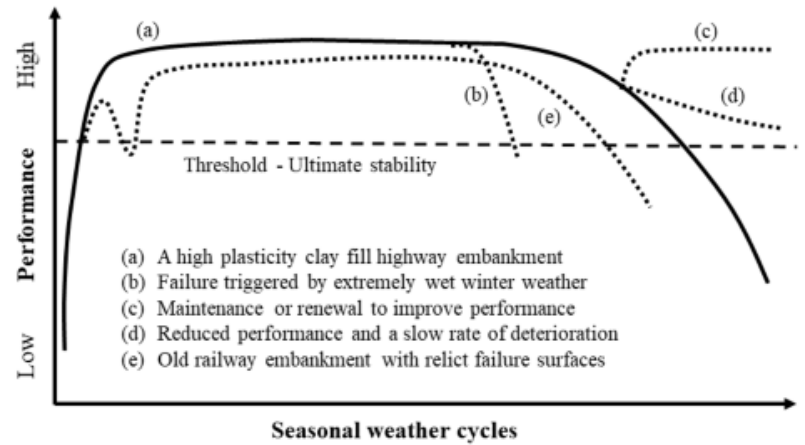

Figure 3 shows the performance of a generic high plasticity clay fill highway embankment over successive seasonal weather cycles. A period of bedding-in and reliable performance is followed by deterioration and then failure due to strain softening of the clay fill, progressive slope failure and ultimate failure of the embankment (curve a). The performance curve can be modified to consider the loading factors, intrinsic 
factors and soil factors affecting an asset or network of assets. For example, extreme loading due to extremely wet winter weather might trigger a slope failure (curve b). Once deterioration has been detected, the performance of the embankment can be improved by maintenance or renewal activities within an appropriate timeframe (curve c). Alternatively, monitoring and inspection might show that an embankment is deteriorating at a slower rate than projected (curve d), so that interventions can be delayed or reduced. The curve for a generic highway embankment can be compared to that for a railway embankment with zones of weakness due to an initial failure (curve e). This curve shows an initial failure soon after construction, which then reduces the performance of the embankment through its life and leads to early deterioration and failure.

Figure 4 The broad mapping of UK transport infrastructure embankments on to a performance curve

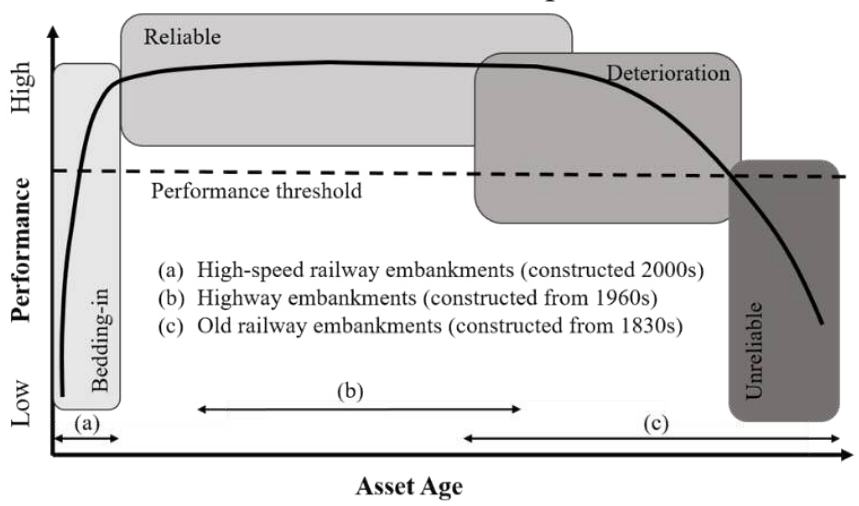

Figure 4 shows how the consideration of asset age can be used to compare and project the relative performance of different types of UK transport infrastructure embankment. High-speed railway embankments are likely to be at or close to peak performance. This is because they are relatively new and they are formed from fill materials that are not likely to degrade in the near future. Highway embankments are likely to be at a stage of reliable performance or approaching a period of deterioration and/or maintenance. This is because they were designed to standards considering classical soil mechanics theory and were constructed using controlled materials. They are relatively homogenous in terms of their geometry, material composition and modes of failure. It is therefore possible to maintain reliable performance by introducing periodic inspections, maintenance and planned interventions in advance of material or asset deterioration. Old railway embankments are likely to be at a stage of initial or advanced deterioration requiring maintenance, reactive interventions or planned replacement. This is because they were empirically designed and constructed, which sometimes resulted in poor material quality and the formation of weaknesses from initial failures. Their age means that they are more likely to have been subjected to many pore water pressure cycles, more pore water pressure extremes and to have undergone material deterioration to accelerate deterioration processes.

\section{Conclusions}

This paper describes how performance curves can be used to compare and forecast the changing performance of transport infrastructure embankments due to physical deterioration processes. This requires an understanding of the physical mechanisms affecting the properties of both the embankments (assets) and the soils from which they are constructed. It also requires access to accurate, consistent and reliable data. As identified by Thurlby (2013), these requirements are often difficult to address when considering many types of physical assets and asset networks. This is also true when considering the performance of the UK's transport infrastructure embankments.

The process of developing performance curves was illustrated by considering the ultimate stability of different types of transport infrastructure embankments over time. Detail was added to generic performance curves by considering the peerreviewed evidence for the drivers, properties and mechanisms causing a loss of soil strength in transport infrastructure embankments. From this, the following can be concluded:

1. Performance curves can be used to evaluate the performance of LLAs over their lifetime. The curves can be modified to consider specific definitions of performance and to compare asset types. For example, the performance curve in Figure 3 shows that the performance of an embankment may be permanently reduced following an initial failure and repair, or may rapidly reduce following an extremely wet winter. It also shows that some embankment types will provide reduced performance but remain stable. This information can be used to identify, plan and prioritise interventions such as monitoring, maintenance and renewal activities. It also allows infrastructure owners and financers to forecast the costs, timing and benefits of interventions to improve the long-term performance of LLAs.

2. Performance curves provide a 'common language' (Bowers et al., 2016) to map the deterioration mechanisms affecting assets or a network of assets. This allows the known and unknown drivers, asset properties, soil properties and deterioration mechanisms to be identified. It is therefore possible to identify and communicate the need for further information or research. For example, the exercise outlined in this paper showed that the deterioration of soils and assets is not fully understood and the evidence relates to a limited number of soil types and full-scale investigations. The peerreviewed literature also lacks information describing the type and current condition of UK transport infrastructure embankments. The labelled performance curves allow this to be identified and communicated. They provide a method for multiple stakeholders (e.g. consultants, infrastructure owners, infrastructure operators, government) to understand the issues, further populate the curves and make holistic decisions about performance.

3. Performance curves can be populated and updated with information showing the current condition of LLAs. The 
curves presented in this paper were derived from information in the peer-reviewed literature or gathered during the manual inspection and monitoring of LLAs. However, there are a growing number of sensing technologies and data sources available to infrastructure owners and managers. Data can be stored and managed using geographic information systems (GIS) including the Geotechnical Data Management System (HAGDMS) for highways and Geotechnical Rail Infrastructure Network Model (GeoRINM) for railways. The volume of data is increasing, as is the complexity of its interpretation to understand deterioration mechanisms and make decisions. Performance curves provide a method to structure the planning, collection and interpretation of large volumes of information describing the performance of long linear assets. This contributes to the UK's infrastructure vision to deliver intelligent design, management and maintenance.

\section{Acknowledgements}

This research is supported by the UK EPSRC-funded ACHILLES Programme (EP/R034575/1) and iSMART Project (EP/K027050/1); including the universities of Newcastle, Southampton, Durham, Loughborough, Leeds, Queen's Belfast, Bath and the British Geological Survey. The team gratefully acknowledges the support received from the programme stakeholders and project partners. Briggs was supported by a Royal Academy of Engineering Industrial Fellowship (2017/18).

\section{References}

Abrams D and Brown M (2017). A case study on geotechnical asset remote monitoring in Network Rail. In Proceedings of the Institution of Civil Engineers-Transport (1-8). Thomas Telford Ltd.

Anderson MG and Kneale PE (1980) Pore water pressure changes in a road embankment. Highway Engineer, 27(5), 1117.

Anderson MG et al. (1982) The influence of shrinkage cracks on pore-water pressures within a clay embankment. Quarterly Journal of Engineering Geology and Hydrogeology, 15(1), 914.

Blight GE (1997) Interactions between the atmosphere and the Earth. Géotechnique, 47(4), 715-767.

Birch GP and Dewar AL (2002). Earthwork failures in response to extreme weather. In Proceedings of the International Conference Railway Engineering 2002, London, UK, July 2002-CD ROM.

Bowers K et al. (2016) Smart Infrastructure. Getting more from strategic assets. Cambridge Centre for Smart Infrastructure \& Construction.

Briggs KM et al (2013) Wet winter pore pressures in railway embankments. Proceedings of the Institution of Civil Engineers-Geotechnical Engineering, 166(5), 451-465.

Briggs KM et al (2016) The influence of tree root water uptake on the long term hydrology of a clay fill railway embankment. Transportation Geotechnics, 9, 31-48.
Briggs KM et al (2017) Failures in transport infrastructure embankments. Engineering Geology, 219, 107-117.

British Standards Institution (2009) 6031 Code of Practice for Earthworks. BSI, London, UK.

Burland JB et al (1977) A study of ground movement and progressive failure caused by a deep excavation in Oxford Clay. Géotechnique, 27(4), 557-591.

Chambers JE et al (2014) 4D electrical resistivity tomography monitoring of soil moisture dynamics in an operational railway embankment. Near Surface Geophysics, 12, $61-72$

Chandler RJ et al (1973) Four long-term failures of embankments founded on areas of landslip. Quarterly Journal of Engineering Geology and Hydrogeology, 6(3-4), 405-422.

Cooper RE (1899) Causes of Earth-slips in the Slopes of Cuttings and Embankments of Railways and How to Prevent or Remedy Them. Second Metropolitan Engineering Conference, 9 June 1899. Minutes of the Proceedings Vol. 138, No. 1899. Thomas Telford, 383-385.

Dixon N et al (2018) In situ measurements of near-surface hydraulic conductivity in engineered clay slopes. Quarterly Journal of Engineering Geology and Hydrogeology, :qjegh2017-059.

Ellis EA and O'Brien AS (2007) Effect of height on delayed collapse of cuttings in stiff clay. Proceedings of the Institution of Civil Engineers-Geotechnical Engineering, 160(2), 73-84.

Garret C and Wale JH (1985) Performance of embankments and cuttings in Gault Clay in Kent. From Proceedings of the Symposium on Failures in Earthworks, Organized by the Institution of Civil Engineers, London, March 6-7, 1985.

Glendinning S et al (2014) Construction, management and maintenance of embankments used for road and rail infrastructure: implications of weather induced pore water pressures. Acta Geotechnica, 9(5), 799-816.

Gunn DA et al (2016) Aged embankment imaging and assessment using surface waves. Proceedings of the Institution of Civil Engineers-Forensic Engineering, 169(4), 149-165.

Gunn DA et al (2018) Deterioration model and condition monitoring of aged railway embankment using non-invasive geophysics. Construction and Building Materials, 170. 668678.

Harrison JWD (1881). Failures in railway Embankments. Minutes of the Proceedings. Vol. 66, No. 1881. Thomas Telford, pp. 258-262.

Hen-Jones RM et al (2017) Seasonal effects on geophysicalgeotechnical relationships and their implications for electrical resistivity tomography monitoring of slopes. Acta Geotechnica, 12(5), 1159-1173.

Highways England. Asset Information Group (2018). Asset data management manual. March 2018. Version: 7.0

Hudacsek P et al (2009) Centrifuge modelling of climatic effects on clay embankments. In Proceedings of the Institution of Civil Engineers-Engineering Sustainability (Vol. 162, No. 2, pp. 91-100). Thomas Telford Ltd. 
Jaroszweski D et al (2015) The impacts of the 28 June 2012 storms on UK road and rail transport. Meteorological Applications. 1;22(3):470-6.

Kluke G et al (2003) A critical look at the bathtub curve. IEEE Transactions on Reliability 52(1): 125-129.

Kovacevic N et al (2001). Progressive Failure in Clay Embankments Due to Seasonal Climate Changes. Proceedings of the International Conference on Soil Mechanics and Geotechnical Engineering Vol. 3. Balkema Publishers, 21272130.

Lees AS et al (2013) Seasonal slope movements in an old clay fill embankment dam. Canadian Geotechnical Journal, 50(5), 503-520.

Leroueil S (2001) Natural slopes and cuts: movement and failure mechanisms. Geotechnique 51 (3), 197-243.

Loveridge FA et al (2010). The impact of climate and climate change on infrastructure slopes, with particular reference to southern England. Quarterly Journal of Engineering Geology and Hydrogeology, 43(4), pp.461-472.

Macdonald GJ et al (2012) The use of soil moisture deficit as a trigger mechanism for targeted monitoring of earthworks slopes. Geological Society, London, Engineering Geology Special Publications, 26(1), 141-149.

Mendes J and Toll DG (2016). Influence of initial water content on the mechanical behaviour of unsaturated sandy clay soil. International Journal of Geomechanics, 16(6), p.D4016005.

Nyambayo VP et al (2004). The influence of permeability on the stability of embankments experiencing seasonal cyclic pore water pressure changes. In Advances in geotechnical engineering: The Skempton conference, Thomas Telford Publishing, London.

O'Brien AS (2007). Rehabilitation of urban railway embankments: investigation, analysis and stabilisation. In: Cue'llar V et al. (Eds.), Proceedings of the 14th European Conference on Soil Mechanics and Geotechnical Engineering, Madrid. Millpress, Amsterdam, the Netherlands, 125-143.

O'Brien AS (2013) The assessment of old railway embankments- time for change? Partial Saturation in Compacted Soils: Géotechnique Symposium in Print 2011, 1932.

Phear A and O'Riordan N (2004) Earthworks for the Channel Tunnel Rail Link High Speed Railway, UK. In Geotechnical Engineering for Transportation Projects (pp. 1621-1628).

Potts DM et al (1990) Finite element analysis of progressive failure of Carsington embankment, Geotechnique 40, No. 1, 79-101.

Potts DM et al (1997) Delayed collapse of cut slopes in stiff clay, Géotechnique 47(5), 953-982.

Ridley A et al (2004) Role of pore water pressures in embankment stability. Proceedings of the Institution of Civil Engineers-Geotechnical Engineering, 157(4), 193-198.

Road Research Laboratory (1952). Soil Mechanics for Road Engineers. HMSO, London.

Rouainia $\mathrm{M}$ et al (2009) Numerical modelling of climate effects on slope stability. Proceedings of the Institution of Civil Engineers - Engineering Sustainability. 162 (2), 81-89.

Scott JM et al (2007) Influence of climate and vegetation on railway embankments. In: Cuellar V et al. (Eds.), Proceedings of the14th European Conference on Soil Mechanics and Geotechnical Engineering. Millpress, Madrid, Amsterdam, 659-664.

Skempton AW (1996) Embankments and cuttings on the early railway. Construction History. 11,33-49.

Skempton AW (1970). First-time slides in overconsolidated clays. Géotechnique, 20(3), 320-324.

Smethurst JA et al (2015) Mechanical and hydrological impacts of tree removal on a clay fill railway embankment. Géotechnique, 65(11), 869-882.

Smethurst JA et al (2017) Current and future role of instrumentation and monitoring in the performance of transport infrastructure slopes. Quarterly Journal of Engineering Geology and Hydrogeology, pp.qjegh2016-080.

Squire JB (1880) Earthwork Slips in the Cuttings and Embankments of Various Railways, with their Causes and Modes of Treatment. Minutes of the Proceedings Vol. 62, No. 1880. Thomas Telford, 272-279.

Stirling RA et al (2017) Modelling the deterioration of the near surface caused by drying induced cracking. Applied Clay Science, 146, 176-185.

Stirling RA et al (2018) The behaviour and influence of desiccation cracking on a full-scale, vegetated infrastructure embankment. In Proceedings of The 7th International Conference on Unsaturated Soils, Hong Kong University of Science and Technology, Hong Kong.

Take WA and Bolton MD (2011) Seasonal ratcheting and softening in clay slopes, leading to first-time failure. Géotechnique 61 (9), 757-769.

Tang AM et al (2018) Atmosphere-vegetation-soil interactions in a climate change context; impact of changing conditions on engineered transport infrastructure slopes in Europe. Quarterly Journal of Engineering Geology and Hydrogeology, pp.qjegh2017-103.

Thurlby R (2013) Managing the asset time bomb: a system dynamics approach. Proceedings of the Institution of Civil Engineers-Forensic Engineering, 166(3), 134-142.

Vaughan PR (1994) Assumption, prediction and reality in geotechnical engineering. Géotechnique, 44(4), 573-609.

Vaughan PR et al (2004) Then and now: some comments on the design and analysis of slopes and embankments. Advances in Geotechnical Engineering. The Skempton Conference. Thomas Telford, London, 241-290 